\title{
14,15-Epoxyeicosatrienoic Acid Suppresses Cigarette Smoke Extract-Induced Apoptosis in Lung Epithelial Cells by Inhibiting Endoplasmic Reticulum Stress
}

\author{
Ganggang Yu ${ }^{a}$ Xiangjun Zeng ${ }^{b}$ Hongxia Wang ${ }^{b}$ Qi Hou ${ }^{c}$ Chunting Tan ${ }^{a}$ \\ Qiufen $X^{a}{ }^{a}$ Haoyan Wang ${ }^{a}$ \\ aThe Department of Respiratory Medicine, Beijing Friendship Hospital, Capital Medical University, \\ Beijing, 'bThe Department of Pathophysiology, Capital Medical University, Beijing, 'Beijing Key \\ Laboratory of New Drug Mechanisms and Pharmacological Evaluation Study, Institute of Materia \\ Medica, Chinese Academy of Medical Sciences and Peking Union Medical College, Beijing, China
}

\section{Key Words}

Cytochrome P450 2J2 • Epoxyeicosatrienoic acids • Apoptosis • Endoplasmic reticulum stress

- Cigarette smoke

\begin{abstract}
Background/Aims: Epoxyeicosatrienoic acids (EETs), a type of lipid mediators produced by cytochrome P450 epoxygenases, exert anti-inflammatory, angiogenic, anti-oxidative and anti-apoptotic effects. However, the role of EETs in cigarette smoke-induced lung injury and the underlying mechanisms are not fully known. The aim of this study was to explore the effects of CYP2J2-EETs on cigarette smoke extracts (CSE)-induced apoptosis in human bronchial epithelial cell line (Beas-2B) and the possible mechanisms involved. Methods: Cytochrome P450 epoxygenase 2J2 (CYP2J2) and its metabolites EETs were assessed by western blotting or LC-MS-MS. Cell viability and apoptosis were determined by MTT assay and AnnexinV-PI staining. Reactive oxygen species (ROS) were assessed by measuring H2DCFDA. Caspase-3, HO-1, MAPK and endoplasmic reticulum (ER) stress-related markers GRP78, p-elF2a, and CHOP were evaluated by western blotting. Results: CSE suppressed expression of both CYP2J2 and EET by Beas-2B cells. CSE also induced apoptosis, the generation of ROS and the ER stress in Beas-2B cells. These changes were abolished by pretreatment with exogenous 14,15 -EET while pretreatment with 14,15-EEZE, a selective EET antagonist, abolished the protective effects of 14,15-EET. In addition, EETs increased the expression of antioxidant enzyme HO-1. Furthermore, 14,15-EET reduced CSE-induced activation of p38 and JNK. Conclusion: The data suggest that CYP2J2-derived EETs protect against CSE-induced lung injury possibly through attenuating ER stress.

Copyright (C) 2015 S. Karger AG, Basel

Haoyan Wang

The Department of Respiratory Medicine, Beijing Friendship Hospital, Capital Medical University, No, 95 Yong An Road, Xichen District, Beijing 100050 (China)

Tel. +8610 63138302, Fax +8610 63138746, E-Mail haoyan_w@163.com
\end{abstract}

KARGER 125 


\begin{tabular}{|c|c|c|}
\hline Cellular Physiology & Cell Physiol Biochem 2015;36:474-486 & \\
\hline and Biochemistry & $\begin{array}{l}\text { DOI: 10.1159/000430113 } \\
\text { Published online: May 11, } 2015\end{array}$ & $\begin{array}{l}\text { O } 2015 \text { S. Karger AG, Basel } \\
\text { www.karger.com/cpb }\end{array}$ \\
\hline
\end{tabular}

\section{Introduction}

Chronic obstructive pulmonary disease (COPD) is characterized by progressive, irreversible airflow limitation caused by emphysema and chronic bronchitis. Cigarette smoke (CS) is the primary risk factor for the development of COPD [1]. CS exposure potentially results in chronic airway inflammation, leading to airway obstruction and inflammatory responses of the alveolar walls, which are associated with lung cell death, lung tissue destruction, and emphysema [2].

The endoplasmic reticulum (ER), an important organelle is responsible for the synthesis and folding of proteins which are required for cell survival and normal cellular functions. Excessive and prolonged stress impairs ER functions resulting in an accumulation of misfolded and unfolded proteins, and even ER stress. It has been shown that ER stress and ER stress-induced cell death have important roles in the pathophysiology of several chronic diseases in humans, including cardiovascular diseases and diabetes [3]. Recent studies have shown that CS can cause ER stress in the lungs of patients with COPD $[4,5]$ and that cigarette smoke extracts (CSE) can induce ER stress and apoptosis in lung epithelial cells [68], suggesting that ER stress may contribute to the pathogenesis of COPD.

Epoxyeicosatrienoic acids (EETs) are arachidonic acid metabolites produced by the cytochrome P450 epoxygenase pathway $[9,10]$. Human cytochrome P450 2J2 (CYP2J2) is the predominant enzyme responsible for EET biosynthesis [11]. There are four regioisomeric EETs, including 5,6-EET, 8,9-EET, 11,12-EET and 14,15-EET. Under action of soluble epoxide hydrolase ( $\mathrm{sEH}$ ), EETs are rapidly hydrolyzed to their corresponding dihydroxyeicosatrienoic acid (DHET) metabolites which are much less biological active than EETs. A number of studies have shown that EETs have anti-inflammatory, antioxidative and antiapoptotic activities [1216]16. In addition, EETs can reduce ER stress signaling in liver, adipose and heart tissues $[17,18]$. CYP2J 2 mRNA and protein have been detected in the human pulmonary epithelial cells, vascular endothelial cells, vascular smooth muscle cells and alveolar macrophages, either in vitro or in vivo ,[11,19]. 14,15-EET is the predominant regioisomer of EETs present in the lung. Recently, Wang et al. [20] have reported that sEH-selective inhibitors, which stabilize EETs by preventing their conversion to DHETs, have significant protective effects on tobacco smoke-induced lung injury in a rat model of COPD. Furthermore, the concentrations of 11,12-EET are higher the exhaled breath condensates of patients with COPD than those of control subjects, while the concentrations of 8,9-EET are lower in COPD patients [21] Although these observations imply that EETs may play an important role in the pathogenesis of COPD, the precise mechanisms of EETs protecting against COPD are still unclear.

In the present study, we assessed the expression of CYP2J2 and the formation of EET in human lung epithelial cell line Beas-2B. We also evaluated the effects of 14,15-EET on the CSE-induced apoptosis in these cells and the possible molecular mechanisms invoved.

\section{Materials and Methods}

\section{Materials}

Human bronchial epithelial cells (BEAS-2B) were purchased from the American Type Culture Collection (ATCC, Rockville, MA, USA).11,12-EET and 14,15-EET were purchased from Cayman Chemical (Ann Arbor, MI, USA). 14,14-EEZE was purchased from Sigma (St. Louis, MO, USA). Solid-phase extraction (SPE) cartridges (Oasis HLB) were from Waters (Milford, MA, USA). Anti-CYP2J2 antibody was from Santa Cruz Biotechnology (Santa Cruz, CA). Monoclonal antibodies against GADPH, glucose-regulated protein 78 (GRP78), C/EBP-homologous protein (CHOP), phospho-eukaryotic initiation factor-2 $\alpha$ (P-eIF $2 \alpha$ ), phosphorERK, ERK, phospho-JNK, JNK, phospho-p38, p38, PD98059, SB203580, and SP600125 were obtained from Cell Signaling (Beverly, MA). Annexin V-FITC apoptosis detection kit was obtained from BD (BD, San Diego, CA). All other chemicals and reagents were purchased from Sigma-Aldrich, unless otherwise specified. 


\section{Cellular Physiology Cell Physiol Biochem 2015;36:474-486 \begin{tabular}{l|l|l} 
DOI: 10.1159/000430113 & (C) 2015 S. Karger AG, Basel
\end{tabular} and Biochemistry Published online: May 11, 2015 www.karger.com/cpb \\ Yu et al.: 14,15-EET Inhibits ER Stress-Associated Apoptosis}

Preparation of CSE

Cigarette smoke extract (CSE) was prepared according to previously described methods, with some modifications [22]. Briefly, 2R4F Kentucky reference cigarettes (The Tobacco Research Institute, University of Kentucky, Lexington, KY) were smoked using a peristaltic pump. Two cigarettes were bubbled through $25 \mathrm{ml}$ of cell growth medium in $8 \mathrm{~min}$, which the solution was adjusted to a pH of 7.4, considered as $100 \%$ strength CSE, and used within 30 min of preparation.

\section{Cell culture}

Human bronchial epithelial cells (Beas-2B) were seeded in M199 medium (Gibco, Grand Island, NY, USA) containing $10 \%$ FBS (HyClone, Logan, UT, USA),and incubated at $37^{\circ} \mathrm{C}$ in a humidified atmosphere with $5 \% \mathrm{CO}_{2}$ and $95 \%$ air. The medium was refreshed every 2-3 days. Cells were used between passages 5 and 25 .

\section{Cell viability assay}

Cell viability was assessed using the MTT assay. Briefly, Beas-2B cells were seeded in 96-well plates containing MTT solution (final concentration of $0.5 \mathrm{mg} / \mathrm{ml}$ ) and incubated for further $4 \mathrm{~h}$ at $37^{\circ} \mathrm{C}$. After removing the medium, the intracellular formazan product was dissolved in $250 \mu \mathrm{l}$ of DMSO. Absorbance of each well was measured at $540 \mathrm{~nm}$ using a microplate reader (Model 680, BioRad). The OD values for the wells containing control cells were considered to be $100 \%$, while the OD values for the experimental cells were expressed as the percentages of the control.

Flow cytometric analysis with annexin-V/propidium iodide staining

Annexin V-FITC and PI double staining was performed using an AnnexinV-FITC apoptosis detection kit (BD, San Diego, CA) according to the manufacturer's protocols. Briefly, cells were harvested, centrifuged at $1500 \mathrm{rpm}$ for 5 minutes, and washed twice with ice-cold PBS. After adding $5 \mu \mathrm{l}$ of Annexin V, $5 \mu \mathrm{l}$ of PI and $500 \mu \mathrm{l}$ of PBS to the cells, the samples were incubated at room temperature for 15 minutes in the dark. Cell apoptosis was analyzed on a FACScan flow cytometer (CyAn ADP, Beckman Coulter, USA). Annexin V-FITCpositive, PI-negative cells were scored as apoptotic. Double-stained cells were considered as either necrotic or late apoptotic cells.

\section{Western blot analysis}

Cells were lysed on ice with $100 \mu \mathrm{l}$ of RIPA lysis buffer. The concentrations of total proteins were measured using a BCA protein assay kit (Pierce). Equal amounts of proteins were separated by 8-15\% SDSPAGE and then transferred to nitrocellulose membranes. The membranes were incubated with primary antibody against CYP2J2 (1:400), caspase-3, GRP78, P-eIF2 $\alpha$, CHOP, phosphor-ERK, ERK, phospho-JNK, JNK, phospho-p38, p38 (1:1000) and GAPDH $(1: 2000)$ overnight at $4{ }^{\circ} \mathrm{C}$ and then with horseradish peroxidase conjugated secondary antibodies (1:4000) for $2 \mathrm{~h}$. After washing with TBST, the specific signals were detected with an enhanced chemiluminescence kit.

\section{Measurement of intracellular ROS}

Intracellular ROS generation was determined with the fluorescent probe H2DCFDA, according to the manufacturer's instructions (Vigorous, Beijing, China). Briefly, Beas-2B cells in the presence or absence of EETs, were stimulated with CSE for $6 \mathrm{~h}$, then incubated with H2DCFDA (final concentration $10 \mu \mathrm{mol} / \mathrm{L}$ ) at $37^{\circ} \mathrm{C}$ for $30 \mathrm{~min}$ in the dark. After washing with fresh medium for three times, the levels of intracellular ROS were measured using a fluorescent microplate reader (BioTek, Winooski, VT, USA) at an emission wavelength of $485 \mathrm{~nm}$ and an excitation wavelength of $530 \mathrm{~nm}$.

\section{Quantification of EETs}

EETs were quantified using the LC/MS/MS method, as previously described [23]. Briefly, cells were harvested and hydrolyzed after adding $200 \mu \mathrm{l}$ of $10 \mathrm{M}$ sodium hydroxide for $20 \mathrm{~min}$ at $60^{\circ} \mathrm{C}$. The solution was neutralized by adding $200 \mu \mathrm{l}$ of $60 \%$ acetic acid and $2 \mathrm{ml}$ of $1 \mathrm{M}$ sodium acetate buffer, PH 6.0. The hydrolyzed samples were cleared by centrifugation at $23000 \mathrm{~g}$ for $10 \mathrm{~min}$ at $0^{\circ} \mathrm{C}$. The supernatants were transferred to fresh tubes and diluted to a concentration of $10 \%$ methanol by the addition of $1.8 \mathrm{~mL}$ water. The diluted supernatant was loaded onto a $1 \mathrm{~mL}$ Oasis HLB SPE cartridge (Waters) on a vacuum manifold. 


\section{Cellular Physiology Cell Physiol Biochem 2015;36:474-486

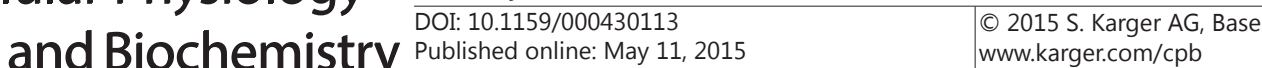 \\ Yu et al.: 14,15-EET Inhibits ER Stress-Associated Apoptosis}

The SPE cartridge was preconditioned by low flow using the sequences of $1 \mathrm{~mL}$ methanol, $1 \mathrm{~mL}$ acetone, 2 $\mathrm{mL}$ hexane, $1 \mathrm{~mL}$ acetone, $1 \mathrm{~mL}$ methanol and $2 \mathrm{~mL}$ water. The cartridge was washed with $3 \mathrm{~mL}$ water and then $1 \mathrm{~mL}$ of $10 \%$ methanol before being allowed to dry under argon for $10 \mathrm{~min}$. The eicosanoid metabolites were collected by elution with $2 \mathrm{~mL}$ anhydrous acetonitrile and then dried under a stream of argon.

$10 \mu \mathrm{l}$ of supernatant was injected onto a high resolution column (Zorbax Eclipse Plus-C18, 4.6×150 $\mathrm{mm}, 1.8 \mu \mathrm{m}$ ). Acetonitrile was increased within $10 \mathrm{~min}$ to $90 \%$ and held for a further 10 min with a flow rate of $0.8 \mathrm{ml} / \mathrm{min}$. The HPLC was coupled to the Agilent 6490 triplequad mass spectrometer with electrospray ionization source. Analysis was performed with selective reaction monitoring (SRM) in negative mode, a gas temperature of $350^{\circ} \mathrm{C}$, a nitrogen stream of 12 liters/min, and a capillary voltage of $4000 \mathrm{~V}$. The SRM transitions monitored were mass-to-charge ratio $(\mathrm{m} / \mathrm{z})$ at $\mathrm{m} / \mathrm{z} 319.3 \rightarrow 167$ for 11,12 -EET, $\mathrm{m} / \mathrm{z} 319.3 \rightarrow 219$ for 14,15-EET, $m / z 319.3 \rightarrow 257$ for 8,9-EET, $m / z$ 319.3 $\rightarrow 191$ for 5,6-EET, respectively.

\section{Statistical analysis}

The results were analyzed using SPSS 16 (SPSS Inc., Chicago, IL, USA). Differences between groups were assessed by one-way ANOVA, while Bonferroni's test was used for multiple comparisons. Data are expressed as the mean \pm SE For all tests, p-values less than 0.05 were considered significant.

\section{Result}

Effect of CSE on CYP2J2 protein expression and 14,15-EET formation

Western blotting showed that 5\% CSE significantly decreased CYP2J2 protein expression by Beas-2B cells after exposure for $24 \mathrm{~h}$ or $36 \mathrm{~h}$ (Fig. 1A). Furthermore, we measured the formation of 14,15-EET, the major biologically active metabolite produced by CYP2J2 in the lung. As expected, 5\% CSE significantly reduced 14,15-EET formation in Beas-2B cells at the same time points (Fig. 1B). These data indicate that CSE induced a decrease in CYP2J2 expression and 14,15-EET formation.

\section{4,15-EET increases cell viability and reduces apoptosis}

The MTT assay showed that compared to the control group, CSE exposure significantly reduced cell viability in dose-dependent manner at $24 \mathrm{~h}$ (Fig. 2A). Meanwhile, the reduction of cell viability was time-dependent from $18 \mathrm{~h}$ to $24 \mathrm{~h}$ of exposure. Furthermore, pretreatment with 14,15-EET $(1 \mu \mathrm{M})$, but not 11,12-EET $(1 \mu \mathrm{M})$, significantly mitigated the loss of cell viability induced by 5\% CSE (Fig. 2A-B). In vitro experements showed that toxicity of CSE increased in a dose- and time-dependent manner in Beas-2B cells. 10\% CSE had severe cytotoxic effect on Beas-2B cells, whereas the concentration of CSE less than $2.5 \%$ had little effect on the apoptotic rate and CYP2J2 expression. Thus, exspore of 5\% CSE for $24 \mathrm{~h}$ was applied in the following experiments.

To determine whether this CSE-induced reduction in cell viability was due to apoptosis, flow cytometry using annexin V-FITC and western blot analysis for cleaved caspase-3 were performed. Flow cytometry showed that CSE markedly increased the rate of apoptosis at $24 \mathrm{~h}$ compared with vehicle-treated cells (Fig. 3A). Western blotting revealed that CSE significantly increased expression of cleaved caspase-3. Pretreatment with 14,15-EET significantly reduced CSE-induced apoptosis, as measured by annexinV-FITC and caspase- 3 staining. We further explored whether 14,15-EEZE, an EET antagonist, could prevent this 14,15-EETmediated protection against CSE-induced apoptosis. Beas-2B cells were pretreated with 14,15-EEZE $(1 \mu \mathrm{M}) 30$ min before the administration of 14,15-EET. As illustrated in Fig. 3A-B, 14,15-EEZE abolished the protection provided by 14,15-EET. Notably, 14,15-EEZE treatment alone did not affect cell apoptosis. These findings indicate a role for 14,15-EET in inhibiting CSE-induced apoptosis.

\section{4,15-EET prevents CSE-induced ER stress}

We investigated whether CSE induces ER stress by measuring the expression levels of GRP78, p-elF2a, and CHOP in Beas-2B cells using western blot analysis. As shown in Fig. 4A, following treatment with $5 \%$ CSE, the amounts of GRP78, p-elF2a, and CHOP significantly KARGER 


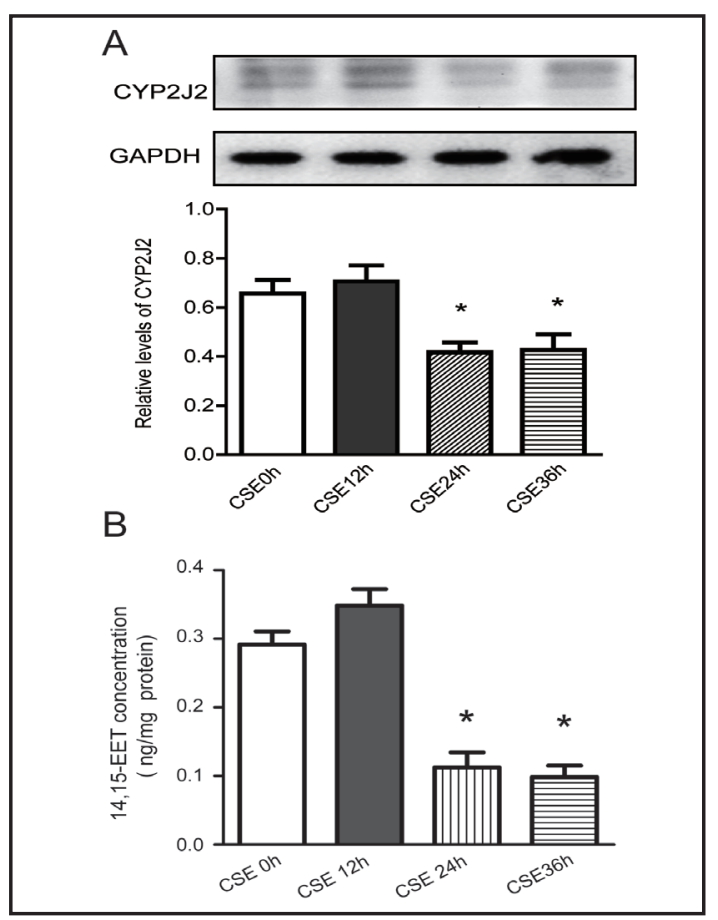

Fig. 1. CSE decreased CYP2J2/EETs in Beas-2B cells. (A) Cells were exposed to 5\% CSE for the indicated time intervals. CYP2J2 expression was assessed by western blotting. GAPDH served as the standard. (B) Similar to CYP2J2, the concentrations of 14,15-EET were also decreased after exposure to $5 \%$ CSE at 24 $\mathrm{h}$ and $36 \mathrm{~h}$ time points. The concentrations of 14,15EET in the harvested cells were measured using LCMS/MS. Values are expressed as the mean \pm SE ( $n=$ 4). ${ }^{*} \mathrm{p}<0.05$ vs. control group.

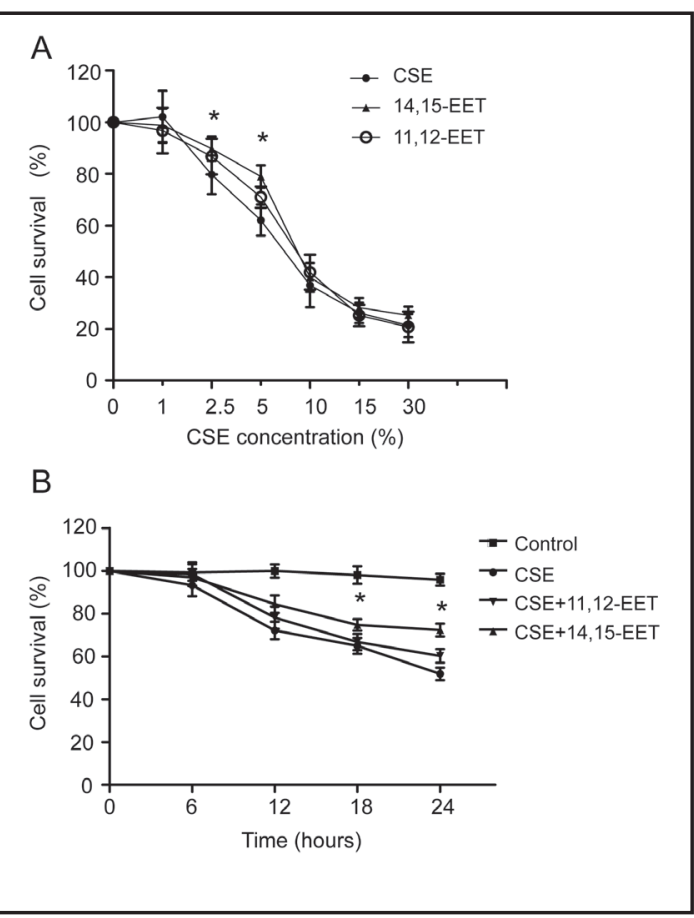

Fig. 2. Effects of cigarette smoke extract (CSE) on the survival of human bronchial epithelial cells (Beas-2B). (A) Cells were pretreated with 11,12-EET $(1 \mu \mathrm{M})$ or 14,15 -EET $(1 \mu \mathrm{M})$ for $1 \mathrm{~h}$, then incubated with increasing concentrations of CSE for further 24 h. 14,15-EET significantly increased the viability of cells exposed to $2.5 \%$ and $5 \%$ CSE. (B) Cells were exposed to $5 \%$ CSE for the indicated times, and cell viability was evaluated using the MTT assay. Cells pretreated with 14,15-EET showed significant increases in cell viability at 18 and $24 \mathrm{~h}$ after CSE exposure. Values are presented as the mean \pm SE $(n=4) .{ }^{*} p<$ 0.05 vs. CSE group.

increased in a time-dependent manner. Next, we investigated the effect of 14,15-EET on CSEinduced ER stress. As illustrated in Fig. 4B, pretreatment with 14,15-EET $(1 \mu \mathrm{M})$ significantly decreased the expression of GRP78, p-elF2a, and CHOP induced by CSE. Furthermore, 14,15-EEZE reversed the 14,15-EET-mediated protection against CSE-induced ER stress, suggesting that 14,15-EET has a potential protective effect against CSE-induced ER stress.

\section{4,15-EET attenuate ROS generation in Beas-2B}

A growing body of evidence has suggested that increased levels of ROS play an important role in CS-induced COPD [24, 25]. In addition, CSE-induced ER stress in lung epithelial cells has been associated with ROS [26]. We sought to determine whether 14,15-EET affects ROS generation after CSE exposure. DCF fluorescence was used to measure ROS in cells exposed to CSE, in the absence or presence of 14,15-EET. In line with published data [27, 28], CSE significantly increased ROS generation in Beas-2B cells 6 hrs after CSE exposure (Fig. 5). Pretreatment with 14,15-EET $(1 \mu \mathrm{M})$ significantly inhibited ROS production, whereas 14,15-EEZE, an antagonist of 14,15-EET blocked 14,15-EET-mediated inhibition (Fig. 5). Cells treated with 14,15-EET or 14,15-EEZE alone did not show a significant change in DCF staining, compared with vehicle-treated cells. These data indicate a role for 14,15-EET in inhibiting CSE-induced ROS production.

\section{KARGER}


Fig. 3. 14,15-EET inhibits CSE-induced apoptosis of Beas-2B cells. Cells were pretreated with 14,15 -EET $(1 \mu \mathrm{M})$ or 14,15 EEZE $(1 \mu \mathrm{M})$ for $1 \mathrm{~h}$ and then exposed to $5 \%$ CSE for further $24 \mathrm{~h}$. Annexin V FACS assay (A) and caspase-3 assay (B) were performed. Values are expressed as the mean \pm SE ( $n=4)$. ${ }^{*} \mathrm{p}<0.05$ vs. control group, ${ }^{\#} \mathrm{p}<0.05$ vs. CSE group, ${ }^{\circledR} \mathrm{p}<0.05$ vs. CSE $+14,15$-EET group.

\section{4,15-EET enhanced the expressions of $\mathrm{HO}-1$ \\ We next assessed the expression} of HO-1, which is an important regulator of lung antioxidant defenses. In accordance with the previous results [22], HO-1 protein was significantly elevated $24 \mathrm{~h}$ after exposure to CSE. Interestingly, pretreatment with 14,15-EET caused a further increase $\mathrm{HO}-1$ protein synthesis after CSE exposure (Fig. 6 A). Furthermore, 14,15-EET reduced the expression of Bach-1, a transcriptional suppresser of $\mathrm{HO}-1$ expression, $24 \mathrm{~h}$ after exposure to CSE (Fig. 6 B). Previously, HO-1 has been shown to inhibit CSE -induced cell death by decreasing ROS generation [29]. Taken together, these results suggest that 14,15-EET may reduce ROS generation through inhibiting Bach-1 then up-regulating HO-1 expression.

\section{MAPK pathways are involved in 14,15-EET-mediated protection MAPK signaling pathways} have been shown to be involved in ER stress-induced apoptosis [30]. To determine whether EETs protect against ER stress-induced apoptosis through MAPK pathways, we evaluated the expression of
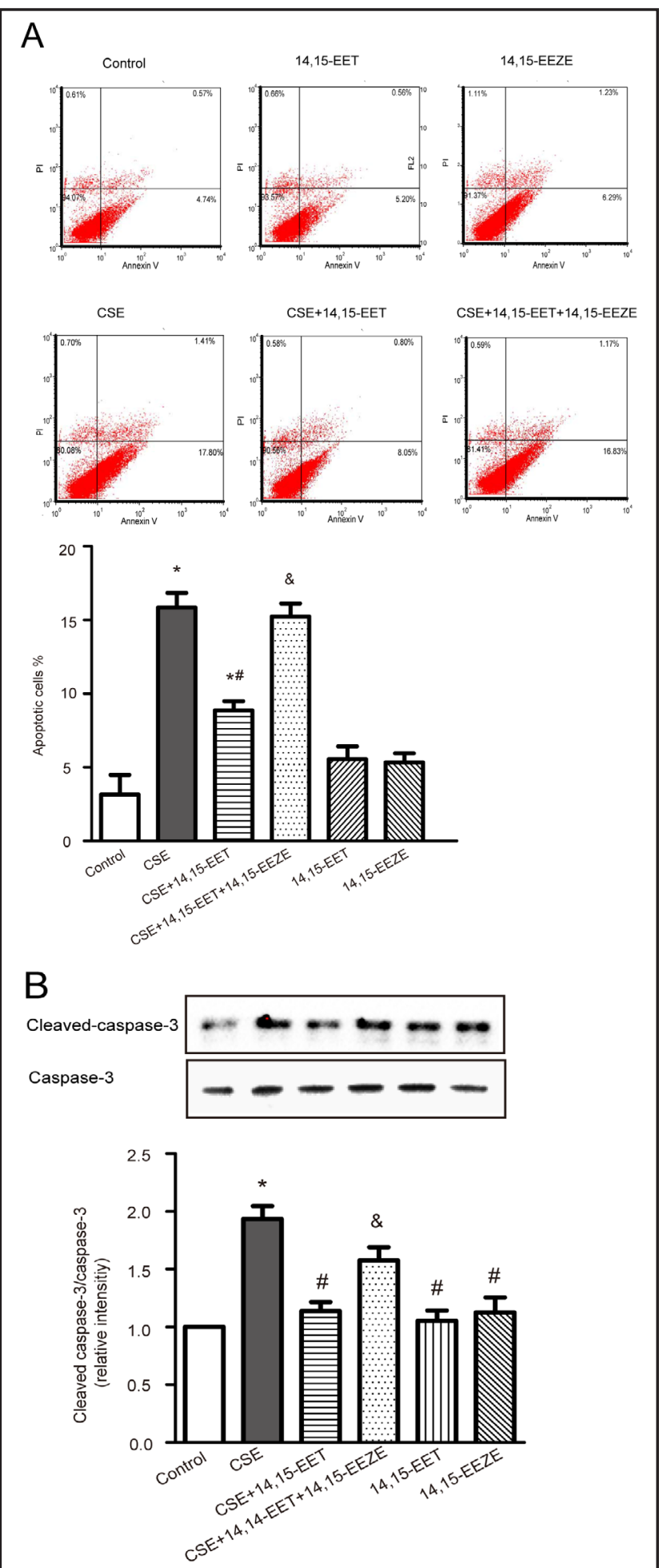

ERK1/2, p38MAPK and JNK by western blot analysis. Consistent with a previous study [31], CSE exposure induced the phosphorylation of ERK1/2, JNK, and p38 MAPK (Fig. 7AB). Pretreatment with an ERK inhibitor (PD98059), a p38 inhibitor (SB203580) and a JNK inhibitor (SP600125) was able to significantly reduce CSE-induced apoptosis (Fig. 7E). In addition, SB203580 and SP600125 also reduced CSE-induced ER stress (Fig. 7CD). Importantly, pretreatment with 14,15-EET inhibited the phosphorylation of JNK and

\section{KARGER}


Fig. 4. 14,15-EET inhibited CSE-induced ER stress signalling. (A) Time-dependent effects of CSE on ER stress-associated proteins. Beas-2B cells were treated with $5 \%$ CSE for the indicated times, and the expression of proteins of GRP78, p-elF2a, and CHOP were assessed by western blotting. (B) Effects of 14,15EET $(1 \mu \mathrm{M})$ and/or 14,15-EEZE $(1 \mu \mathrm{M})$ on ER stress signalling 24 $\mathrm{h}$ after CSE exposure. Values are the mean \pm SE (n =4). ${ }^{*} \mathrm{p}<0.05$, vs. control group, ${ }^{\&} \mathrm{p}<0.05$ vs. CSE+14,15-EET group.

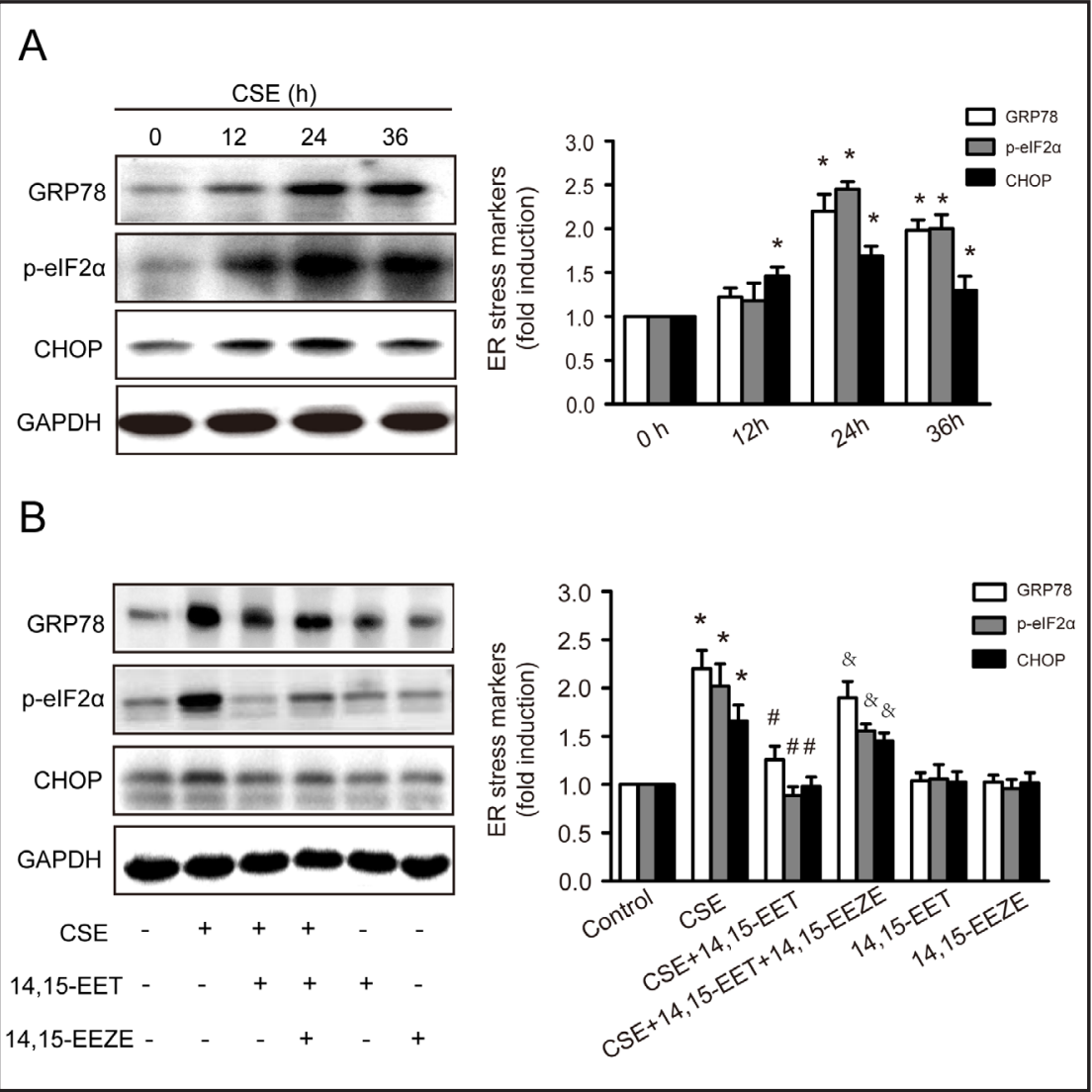

Fig. 5. 14,15-EET attenuated CSE-induced ROS production in Beas-2B cells. (A) ROS was measured using H2DCFDA staining by photofluorography. (Scale bar, $25 \mu \mathrm{m}$. magnification, $\times 100$ ). (B) The rate of ROS production was determined by a fluorescence plate reader, and the relative change in fluorescence intensity was expressed as percent change from control at $100 \%$. Values are expressed as the mean $\pm \operatorname{SE}(n=6)$. ${ }^{*} \mathrm{p}<0.05$ vs. control group, ${ }^{\#} \mathrm{p}<0.05$ vs. CSE group. ${ }^{\circledR} \mathrm{p}<0.05$ vs. CSE $+14,15$-EET group.
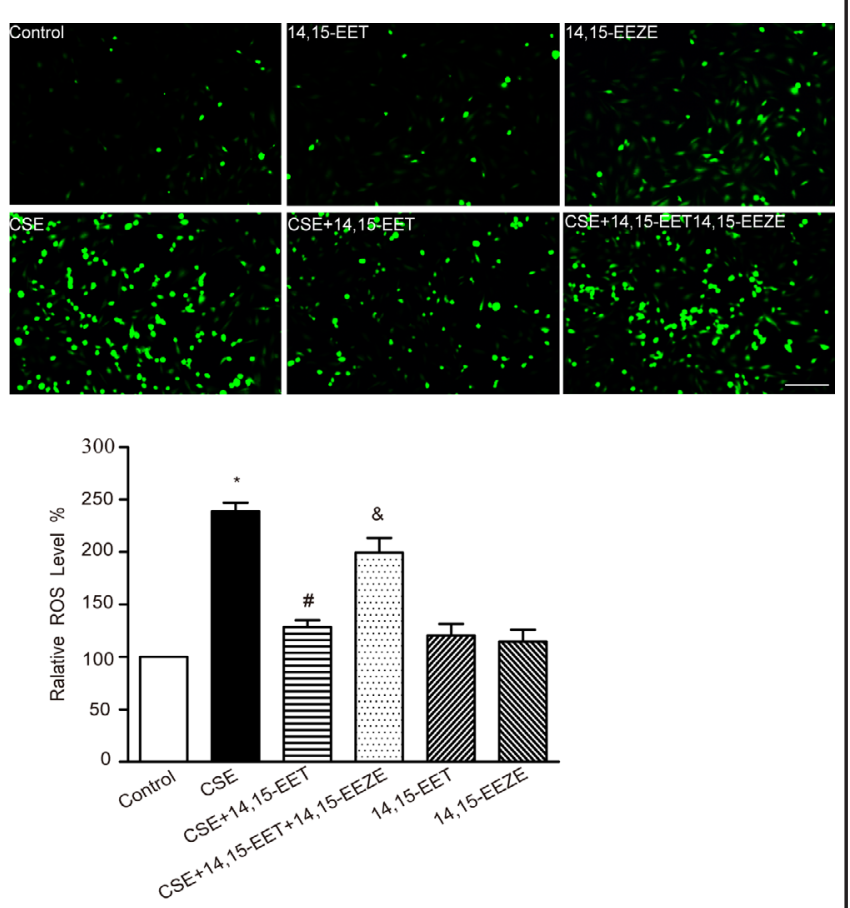

p38 MAPK, but less affected the phosphorylation of ERK1/2 in Beas-2B cells (Fig. 7A-B), suggesting that 14,15-EET may protect CSE-induced apoptosis, at least partially through the p38 MAPK and JNK signalling pathways. 
Fig. 6. 14,15-EET increased HO-1 and decreased Bach-1 expression after CSE exposure. HO-1 and Bach-1 expressions were assessed by western blotting. GAPDH was served as the standard. Values are presented as the mean \pm SE $(n=3)$. ${ }^{*} \mathrm{p}<0.05$ vs. control group, ${ }^{\#} \mathrm{p}<0.05$ vs. CSE group.
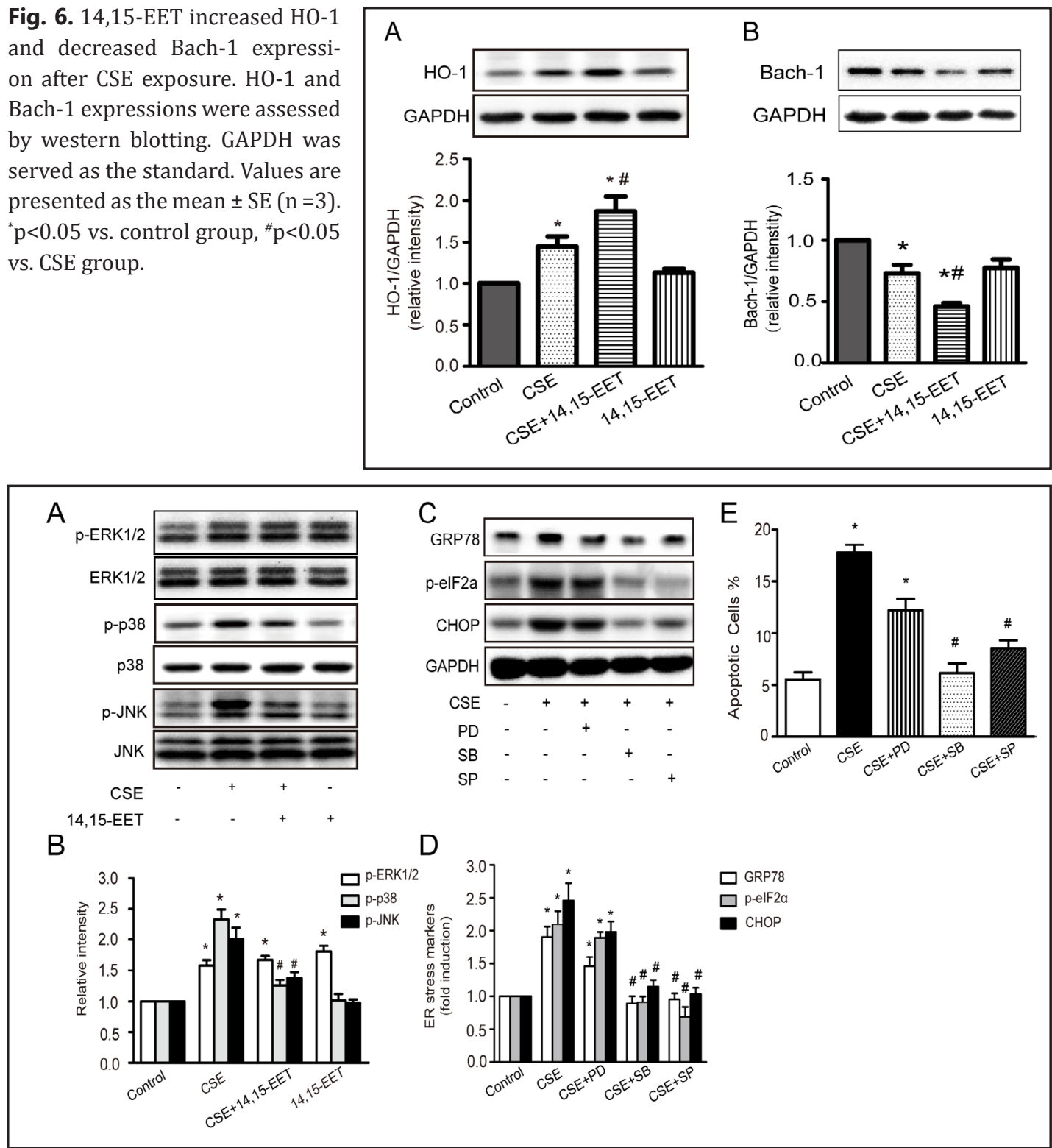

Fig. 7. 14,15-EET suppressed CSE-induced apoptosis by inhibiting MAPK-dependent signalling pathways in Beas-2B cells. (A and B) Effects of 14,15-EET on the activity of phospho-ERK1/2, phospho-p38, and phospho-JNK in Beas-2B cells treated with 5\% CSE. (C and D) Cells were incubated with or without pretreatment with MAPK inhibitors (PD98059, an ERK inhibitor, $10 \mu \mathrm{M}$; SB, SB203580, a p38 inhibitor, $10 \mu \mathrm{M}$; SP, SP600125, a JNK inhibitor, $10 \mu \mathrm{M}$ ) for $30 \mathrm{~min}$ and then exposed to $5 \%$ CSE for further $24 \mathrm{~h}$. The protein levels were analyzed by western blotting. Values are expressed as the mean $\pm \mathrm{SE}(\mathrm{n}=3) .{ }^{*} \mathrm{p}<0.05$ vs. control group, ${ }^{\text {p }}<0.05$ vs. CSE group.

\section{Discussion}

In the present study, we demonstrated that CSE suppressed CYP2J2 expression and decreased 14,15-EET formation in human pulmonary epithelial cells. Importantly, pretreatment with 14,15-EET attenuated CSE-induced ER stress and cell apoptosis. Moreover, 14,15-EET inhibited ROS production and up-regulated the expression of the antioxidant 


\section{Cellular Physiology Cell Physiol Biochem 2015;36:474-486 \\ \begin{tabular}{l|l|l}
\hline DOI: 10.1159/000430113 & (c) 2015 S. Karger AG, Basel
\end{tabular} \\ \begin{tabular}{l|l} 
and Biochemistry Published online: May 11, 2015 & www.karger.com/cpb
\end{tabular} \\ Yu et al.: 14,15-EET Inhibits ER Stress-Associated Apoptosis}

HO-1 after CSE exposure. Taken together, these findings suggest that the CYP2J2-EET system might be associated with regulating CSE-induced lung injury and protect against COPD progression by relieving ER stress and oxidative stress.

Human P450 2J2 (CYP2J2) is the predominant CYP epoxygenase that is responsible for the biosynthesis of EETs. It has been reported that CYP2J2 gene expression is repressed in the bronchial biopsies obtained from smokers compared to those of nonsmokers [32]. Our data showed that CSE exposure decreased the expression of CYP2J2 protein and the formation of 14,15-EET in human bronchial epithelial cells. In addition, other CYP epoxygenases like CYP2C8, CYP2C9 are also involved in the synthesis of EETs. Similarly, Deng et al. [33] have shown that increased CYP2J2 and CYP2C8-mediated EET biosynthesis and decreased sEHmediated EET hydrolysis attenuate vascular inflammatory in lung. Thum et al. [32] have reported that CYP2J2 gene expression was repressed in bronchial biopsies of smokers, but CYP2C9 expression was induced. A recent study has shown that that 2.5\% CSE inhibits the expression of CYP2C8 but does not alter the expression of CYP2J2 in NCI-H292 cells [34]. However, our data revealed that 5\% CSE exposure decreased the expression of CYP2J2 protein and the formation of 14,15-EET in Beas-2B cells. These disparate observations may regard to differences in the cell types and the concentration of the CSE used. Although the exact mechanisms that down-regulate CYP2J2 expression after CSE exposure are still unclear, there may be some potential mediators that suppress the transcriptional binding factors. It has been shown that ROS affects the metabolism of epoxygenases, thus leading to oxidative stress that may interfere with the balance of cellular redox after exposure to CSE $[35,36]$. These changes might cause the activation of the cyclooxygenase mediated metabolism of arachidonic acid and the suppression of the epoxygenase metabolic pathways. It has been suggested that nitrative stress can down-regulate CYP2J2 fatty acid epoxygenase possibly through stimulating the expression of the downstream AP-1 factor c-fos via the p38 and ERK signalling pathways [37]. In addition, inflammatory cytokines may also mediate the suppression of CYP450 gene transcription under inflammatory conditions [38]. Whether regulation of CYP2J2 expression is mediated by the above mechanisms remains to be explored.

On the other hand, the concentrations of cellular EETs are also regulated by the degrading enzymes, especially the soluble epoxide hydrolases (sEH). Thus, inhibition of this pathway might likely increase the EET concentrations. It has been shown that sEH gene expression is up-regulated in the lung of mice after exposed cigarette smoke [39]. Ma and colleagues have also found that cigarette smoking slightly increases the levels of sEH in bronchial epithelial cells [34]. Furthermore, it has been observed that soluble epoxide hydrolase inhibitors (sEHIs) improves lung function and attenuates lung inflammation and emphysematous changes in a rat model after exposure to tobacco smoke [20], suggesting that sEHI action is involved in the stabilization of largely anti-inflammatory lipid epoxides, including EETs, and the reduction in the production of largely proinflammatory lipid-1,2 diols. However, the exact mechanisms of EETs on CSE-induced lung cell damage remain unclear. The apoptosis of lung epithelium cell, alveolar septal and endothelial cells is important in the pathogenesis of COPD [40]. In our best knowledge, it is the first report showing that CSE altered the expression of CYP2J2-EET in lung epithelium cells and that 14,15-EET reduced CSE induced epithelial cell apoptosis by attenuating ER stress. These data support a concept that the CYP2J2-EET system may play an important role in the pathogenesis of COPD.

A growing body of evidence has indicated that exposure to common lung irritants, such as cigarette smoke, may increase the accumulation of misfolded proteins in the endoplasmic reticulum (ER), causing ER stress and ER stress-induced apoptosis and, subsequently, the activation of the unfolded protein response (UPR) signalling cascades [5, 41-43]. It is well known that GRP78 is an ER-chaperon protein and plays a crucial role in the regulation of dynamic homeostasis of the ER. GRP78 is also a maker for ER stress. Phosphorylated eIF2a, a component of the PERK arm of the UPR, mediates the attenuation of mRNA translation and reduces the burden of protein folding in the ER lumen. CHOP is induced by ER stress at the transcription level and plays a key role in ER stress-induced apoptosis. Data of 
the present study showed that CSE induced the expression of GRP78, peIF- $2 \alpha$ and CHOP, whereas pretreatment with 14,15-EET significantly decreased CSE-induced expression of GRP78, peIF- $2 \alpha$ and CHOP proteins, suggesting that EET might protect lung epithelial cells from apoptosis by attenuating the ER stress PERK pathway.

Reactive oxygen species (ROS) are important biological mediators in physiology and pathology. Although ROS are essential for cellular functions, they are also potentially toxic. ROS are capable of damaging DNA, RNA, and proteins and degrading essential cellular molecules. ROS are closely linked with ER stress. High level of ROS can be an essential component of the events leading to protein misfolding in the ER and ER stress-induced apoptosis [26, 27]. Our data showed that CSE exposure increased ROS generation, which was attenuated by pretreatment with 14,15-EET, whereas its antagonist 14,15-EEZE abolished the effects of 14,15-EET, suggesting that EETs might attenuate ER stress by scavenging the accumulation of ROS-induced by CSE.

HO-1, an important antioxidant enzyme, has a key role in ROS generation. Recently, HO-1 has been shown to protect lung epithelial cells against CSE-induced cell death by preserving cellular ATP levels [22] and by down-regulating apoptosis and autophagy-related signaling [44]. In addition, it has been shown that HO-1 mediates ER stress-induced apoptosis by down-regulating CHOP protein expression [45]. In the present study, HO-1 protein was markedly elevated in Beas-2B cells after exposure to CSE. Pretreatment with 14,15-EET caused a further increase in the expression of HO-1 protein. In addition, 14,15-EET reduced the expression of Bach-1, a transcriptional suppresser of HO-1 expression, suggesting EETs may stimulate HO-1 expression via the suppression of Bach 1. These data imply that the EET-mediated protection against CSE-induced ER stress and apoptosis may occur through the upregulation of HO-1, which then suppresses ROS formation, It is known that p-Akt/ GSK-3 $\beta$ signaling pathways are participated in the interaction between EET and Bach 1 [33]. In addition, nuclear factor erythroid 2-related factor 2 (Nrf2) is a major regulator of HO-1 induction. It has been reported that Nrf2 plays critical role in regulating transactivation of CYP2J2 by c-Jun/Nrf2 dimers [46]. Goven and colleagues have also shown that CSE affects HO-1 expression and nuclear Nrf2/Bach1 translocation through ERK(1/2) and JNK signalling pathways. Again, the exact mechanism by how EETs regulate HO-1 expression after CSE exposure needs to be further studied.

The mitogen-activated protein kinase (MAPK) pathway is a ubiquitous intracellular signalling pathway consisting of extracellular signal regulated kinase 1/2 (ERK1/2), p38 and c-Jun NH2-terminal kinase (JNK). It regulates cellular proliferation, differentiation and apoptosis, and also plays an important regulatory role in ER stress-induced apoptosis [30]. Our data showed that EET significantly inhibited CSE-induced phosphorylation of p38 and JNK but did not significantly alter the phosphorylation of ERK1/2. These suggest that EET might mediate ER stress-induced apoptosis partially through the inhibition of the p38 and JNK pathway.

In summary, the present study provides insight into the potential protective role of CYP2J2-derived 14,15-EET in CSE-induced lung injury. Specifically, EET protect lung epithelial cells against CSE-induced apoptosis, which is likely mediated through attenuating ER stress. Our data suggest that the CYP2J2-EET system may be a potential target for treating cigarette smoke-induced COPD.

\section{Acknowledgments}

This study was supported by Beijing Municipal Natural Science Foundation (7142046) and grant Shou Fa 2011-2002-03 from Beijing Municipal Health Bureau. 


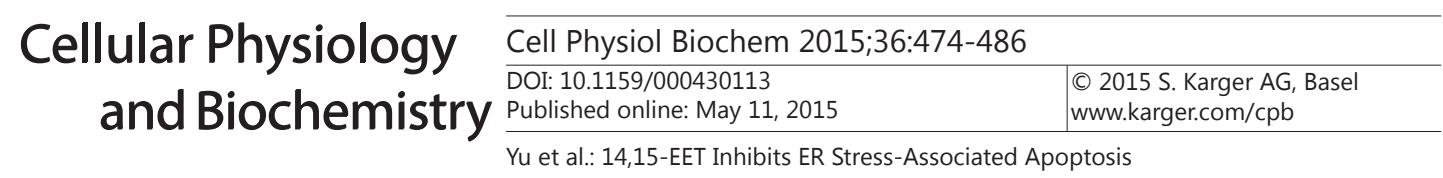

\section{Disclosure Statement}

\section{The authors declare that they have no conflict of interest}

\section{References}

1 Vestbo J, Hurd SS, Agusti AG, Jones PW, Vogelmeier C, Anzueto A, Barnes PJ, Fabbri LM, Martinez FJ, Nishimura M, Stockley RA, Sin DD, Rodriguez-Roisin R: Global strategy for the diagnosis, management, and prevention of chronic obstructive pulmonary disease: GOLD executive summary. Am J Respir Crit Care Med 2013;187:347-365.

2 Tuder RM, Petrache I: Pathogenesis of chronic obstructive pulmonary disease. J Clin Invest 2012;122:2749-2755.

3 Ozcan L, Tabas I: Role of endoplasmic reticulum stress in metabolic disease and other disorders. Annu Rev Med 2012;63:317-328.

4 Wei J, Rahman S, Ayaub EA, Dickhout JG, Ask K: Protein misfolding and endoplasmic reticulum stress in chronic lung disease. Chest 2013;143:1098-1105.

5 Ribeiro CM, O'Neal WK: Endoplasmic reticulum stress in chronic obstructive lung diseases. Curr Mol Med 2012;12:872-882.

6 Kamp DW, Liu G, Cheresh P, Kim SJ, Mueller A, Lam AP, Trejo H, Williams D, Tulasiram S, Baker M, Ridge K, Chandel NS, Beri R: Asbestos-induced alveolar epithelial cell apoptosis. The role of endoplasmic reticulum stress response. Am J Respir Cell Mol Biol 2013;49:892-901.

7 Somborac-Bacura A, van der Toorn M, Franciosi L, Slebos DJ, Zanic-Grubisic T, Bischoff R, van Oosterhout AJ: Cigarette smoke induces endoplasmic reticulum stress response and proteasomal dysfunction in human alveolar epithelial cells. Exp Physiol 2013;98:316-325.

8 Jorgensen E, Stinson A, Shan L, Yang J, Gietl D, Albino AP: Cigarette smoke induces endoplasmic reticulum stress and the unfolded protein response in normal and malignant human lung cells. BMC Cancer 2008;8:229.

9 Morisseau C, Hammock BD: Impact of soluble epoxide hydrolase and epoxyeicosanoids on human health. Annu Rev Pharmacol Toxicol 2013;53:37-58.

10 Spector AA: Arachidonic acid cytochrome P450 epoxygenase pathway. J Lipid Res 2009;50:S52-56.

11 Xu M, Ju W, Hao H, Wang G, Li P: Cytochrome P450 2J2: distribution, function, regulation, genetic polymorphisms and clinical significance. Drug Metab Rev 2013;45:311-352.

12 Yan G, Chen S, You B, Sun J: Activation of sphingosine kinase-1 mediates induction of endothelial cell proliferation and angiogenesis by epoxyeicosatrienoic acids. Cardiovasc Res 2008;78:308-314.

13 Thomson SJ, Askari A, Bishop-Bailey D: Anti-inflammatory effects of epoxyeicosatrienoic acids. Int J Vasc Med 2012;2012:605101.

14 Node K, Huo Y, Ruan X, Yang B, Spiecker M, Ley K, Zeldin DC, Liao JK: Anti-inflammatory properties of cytochrome P450 epoxygenase-derived eicosanoids. Science 1999;285:1276-1279.

15 Spector AA, Norris AW: Action of epoxyeicosatrienoic acids on cellular function. Am J Physiol Cell Physiol 2007;292:C996-1012.

16 Hen W, Zheng G, Yang S, Ping W, Fu X, Zhang N, Wang DW, Wang J: CYP2J2 and EETs Protect against Oxidative Stress and Apoptosis in Vivo and in Vitro Following Lung Ischemia/Reperfusion. Cell Physiol Biochem 2014;33:1663-1680.

17 Bettaieb A, Nagata N, AbouBechara D, Chahed S, Morisseau C, Hammock BD, Haj FG: Soluble epoxide hydrolase deficiency or inhibition attenuates diet-induced endoplasmic reticulum stress in liver and adipose tissue. J Biol Chem 2013;288:14189-14199.

18 Wang X, Ni L, Yang L, Duan Q Chen C, Edin ML, Zeldin DC, Wang DW: CYP2J2-derived epoxyeicosatrienoic acids suppress endoplasmic reticulum stress in heart failure. Mol Pharmacol 2014;85:105-115.

19 Leclerc J, Tournel G, Courcot-Ngoubo Ngangue E, Pottier N, Lafitte JJ, Jaillard S, Mensier E, Lhermitte M, Broly F, Lo-Guidice JM: Profiling gene expression of whole cytochrome P450 superfamily in human bronchial and peripheral lung tissues: Differential expression in non-small cell lung cancers. Biochimie 2010;92:292-306. 


\section{Cellular Physiology Cell Physiol Biochem 2015;36:474-486 \begin{tabular}{l|l} 
DOI: 10.1159/000430113 & (C) 2015 S. Karger AG, Basel
\end{tabular} www.karger.com/cpb \\ Yu et al.: 14,15-EET Inhibits ER Stress-Associated Apoptosis}

20 Wang L, Yang J, Guo L, Uyeminami D, Dong H, Hammock BD, Pinkerton KE: Use of a soluble epoxide hydrolase inhibitor in smoke-induced chronic obstructive pulmonary disease. Am J Respir Cell Mol Biol 2012;46:614-622.

21 Fritscher LG, Post M, Rodrigues MT, Silverman F, Balter M, Chapman KR, Zamel N: Profile of eicosanoids in breath condensate in asthma and COPD. J Breath Res 2012;6:026001.

22 Slebos DJ, Ryter SW, van der Toorn M, Liu F, Guo F, Baty CJ, Karlsson JM, Watkins SC, Kim HP, Wang X, Lee JS, Postma DS, Kauffman HF, Choi AM: Mitochondrial localization and function of heme oxygenase-1 in cigarette smoke-induced cell death. Am J Respir Cell Mol Biol 2007;36:409-417.

23 Arnold C, Markovic M, Blossey K, Wallukat G, Fischer R, Dechend R, Konkel A, von Schacky C, Luft FC, Muller DN, Rothe M, Schunck WH: Arachidonic acid-metabolizing cytochrome P450 enzymes are targets of \{omega\}-3 fatty acids. J Biol Chem 2010;285:32720-32733.

24 Kirkham PA, Barnes PJ: Oxidative stress in COPD. Chest 2013;144:266-273.

25 Nemmar A, Raza H, Subramaniyan D, Yasin J, John A, Ali BH, Kazzam EE: Short-term systemic effects of nose-only cigarette smoke exposure in mice: role of oxidative stress. Cell Physiol Biochem 2013;31:15-24.

26 Kenche H, Baty CJ, Vedagiri K, Shapiro SD, Blumental-Perry A: Cigarette smoking affects oxidative protein folding in endoplasmic reticulum by modifying protein disulfide isomerase. FASEB J 2013;27:965-977.

27 Tagawa Y, Hiramatsu N, Kasai A, Hayakawa K, Okamura M, Yao J, Kitamura M: Induction of apoptosis by cigarette smoke via ROS-dependent endoplasmic reticulum stress and CCAAT/enhancer-binding proteinhomologous protein (CHOP). Free Radic Biol Med 2008;45:50-59.

28 Bazzini C, Rossetti V, Civello DA, Sassone F, Vezzoli V, Persani L, Tiberio L, Lanata L, Bagnasco M, Paulmichl M, Meyer G, Garavaglia ML: Short- and long- term effects of cigarette smoke exposure on glutathione homeostasis in human bronchial epithelial cells. Cell Physiol Biochem 2013;32:129-145.

29 Namba F, Go H, Murphy JA, La P, Yang G, Sengupta S, Fernando AP, Yohannes M, Biswas C, Wehrli SL, Dennery PA: Expression level and subcellular localization of heme oxygenase-1 modulates its cytoprotective properties in response to lung injury: a mouse model. PLoS One 2014;9:e90936.

30 Darling NJ, Cook SJ: The role of MAPK signalling pathways in the response to endoplasmic reticulum stress. Biochim Biophys Acta 2014;1843:2150-2163.

31 Moon HG, Zheng Y, An CH, Kim YK, Jin Y: CCN1 secretion induced by cigarette smoking extracts augments IL-8 release from bronchial epithelial cells. PLoS One 2013;8:e68199.

32 Thum T, Erpenbeck VJ, Moeller J, Hohlfeld JM, Krug N, Borlak J: Expression of xenobiotic metabolizing enzymes in different lung compartments of smokers and nonsmokers. Environ Health Perspect 2006;114:1655-1661.

33 Deng Y, Edin ML, Theken KN, Schuck RN, Flake GP, Kannon MA, DeGraff LM, Lih FB, Foley J, Bradbury JA, Graves JP, Tomer KB, Falck JR, Zeldin DC, Lee CR: Endothelial CYP epoxygenase overexpression and soluble epoxide hydrolase disruption attenuate acute vascular inflammatory responses in mice. Faseb J 2011;25:703-713.

34 Ma WJ, Sun YH, Jiang JX, Dong XW, Zhou JY, Xie QM: Epoxyeicosatrienoic acids attenuate cigarette smoke extract-induced interleukin-8 production in bronchial epithelial cells. Prostaglandins Leukot Essent Fatty Acids DOI:10.1016/j.plefa.2014.10.006.

35 Sodhi K, Puri N, Inoue K, Falck JR, Schwartzman ML, Abraham NG: EET agonist prevents adiposity and vascular dysfunction in rats fed a high fat diet via a decrease in Bach 1 and an increase in HO-1 levels. Prostaglandins Other Lipid Mediat 2012;98:133-142.

36 Raza H, John A, Nemmar A: Short-term effects of nose-only cigarette smoke exposure on glutathione redox homeostasis, cytochrome P450 1A1/2 and respiratory enzyme activities in mice tissues. Cell Physiol Biochem 2013;31:683-692.

37 Cui PH, Lee AC, Zhou F, Murray M: Impaired transactivation of the human CYP2J2 arachidonic acid epoxygenase gene in HepG2 cells subjected to nitrative stress. Br J Pharmacol 2010;159:1440-1449.

38 Theken KN, Deng Y, Kannon MA, Miller TM, Poloyac SM, Lee CR: Activation of the acute inflammatory response alters cytochrome P450 expression and eicosanoid metabolism. Drug Metab Dispos 2011;39:2229.

39 Maresh JG, Xu H, Jiang N, Gairola CG, Shohet RV: Tobacco smoke dysregulates endothelial vasoregulatory transcripts in vivo. Physiol Genomics 2005;21:308-313.

40 Comer DM, Kidney JC, Ennis M, Elborn JS: Airway epithelial cell apoptosis and inflammation in COPD, smokers and nonsmokers. Eur Respir J 2013;41:1058-1067. 


\section{Cellular Physiology Cell Physiol Biochem 2015;36:474-486 \begin{tabular}{l|l} 
DOI: 10.1159/000430113 & O 2015 S. Karger AG, Basel \\
and Biochemistry & Published online: May 11, 2015
\end{tabular} \\ Yu et al.: 14,15-EET Inhibits ER Stress-Associated Apoptosis}

41 Malhotra D, Thimmulappa R, Vij N, Navas-Acien A, Sussan T, Merali S, Zhang L, Kelsen SG, Myers A, Wise R, Tuder R, Biswal S: Heightened endoplasmic reticulum stress in the lungs of patients with chronic obstructive pulmonary disease: the role of Nrf2-regulated proteasomal activity. Am J Respir Crit Care Med 2009;180:1196-1207.

42 He B, Luo B, Chen Q, Zhang L: Cigarette smoke extract induces the expression of GRP78 in A549 cells via the p38/MAPK pathway. Mol Med Rep 2013;8:1683-1688.

43 Tanjore H, Blackwell TS, Lawson WE: Emerging evidence for endoplasmic reticulum stress in the pathogenesis of idiopathic pulmonary fibrosis. Am J Physiol Lung Cell Mol Physiol 2012;302:L721-729.

44 Kim HP, Wang X, Chen ZH, Lee SJ, Huang MH, Wang Y, Ryter SW, Choi AM: Autophagic proteins regulate cigarette smoke-induced apoptosis: protective role of heme oxygenase-1. Autophagy 2008;4:887-895.

45 Kim HP, Pae HO, Back SH, Chung SW, Woo JM, Son Y, Chung HT: Heme oxygenase-1 comes back to endoplasmic reticulum. Biochem Biophys Res Commun 2011;404:1-5.

46 Lee AC, Murray M: Up-regulation of human CYP2J2 in HepG2 cells by butylated hydroxyanisole is mediated by c-Jun and Nrf2. Mol Pharmacol 2010;77:987-994.

47 Goven D, Boutten A, Lecon-Malas V, Boczkowski J, Bonay M: Prolonged cigarette smoke exposure decreases heme oxygenase-1 and alters Nrf2 and Bach1 expression in human macrophages: roles of the MAP kinases ERK(1/2) and JNK. Febs Lett 2009;583:3508-3518. 